\title{
Care of hospitalized infants and their families during the COVID-19 pandemic: an international survey
}

\author{
Ita Litmanovitz $\mathbb{1}^{1,2} \cdot$ Dalia Silberstein ${ }^{1} \cdot$ Samantha Butler ${ }^{3,4} \cdot$ Dorothy Vittner $^{5}$
}

Received: 7 October 2020 / Revised: 19 January 2021 / Accepted: 22 January 2021 / Published online: 23 March 2021

(c) The Author(s), under exclusive licence to Springer Nature America, Inc. 2021

\begin{abstract}
This research study explored changes in family-centered care practices for hospitalized infants and families due to the COVID-19 pandemic. This exploratory descriptive study used a 49-item online survey, distributed to health care professionals working with hospitalized infants and families. The sample consisted of 96 participants from 22 countries. Prior to the COVID-19 pandemic, $87 \%$ of units welcomed families and $92 \%$ encouraged skin-to-skin care. During the pandemic, family presence was restricted in $83 \%$ of units, while participation in infant care was restricted in $32 \%$. Mediumsized (20-40 beds) units applied less restriction than small $(<20$ beds) units $(p=0.03)$. Units with single-family rooms that did not restrict parental presence, implemented fewer restrictions regarding parents' active participation in care $(p=0.02)$. Restrictions to families were not affected by geographic infection rates or developmental care education of health care professionals. Restrictions during the pandemic increased separation between the infant and family.
\end{abstract}

\section{Background}

Coronavirus disease 2019 (COVID-19) is defined as illness caused by a novel virus now called severe acute respiratory syndrome coronavirus 2 . On January 30th, 2020, the World Health Organization declared the COVID-19 outbreak a global health emergency and on March 11th, 2020, the virus was declared a global pandemic. To date, COVID-19 has spread to most of the world with only a few remote locations reporting no cases [1].

As the understanding of COVID-19 continues to evolve, interim guidance has been issued by international health organizations [1, 2]. Limiting transmission of COVID-19 is an essential component of care to patients in the hospital

Ita Litmanovitz

italitman@gmail.com

1 Neonatal Department, Meir Medical Center, Kfar Saba, Israel

2 Sackler Faculty of Medicine, Tel Aviv University, Tel Aviv, Israel

3 Department of Psychiatry, Boston Children's Hospital, Boston, MA, USA

4 Department of Psychiatry, Harvard Medical School, Boston, MA, USA

5 Fairfield University, Egan School of Nursing and Health Studies, Fairfield, CT, USA environment. The infection control interventions to reduce transmission of COVID-19 in hospital environments include universal source control (covering the nose and mouth to contain respiratory secretions), early identification and isolation of patients with suspected disease, the use of appropriate personal protective equipment when caring for patients with COVID-19, and environmental disinfection along with restrictions of hospital visitors. The Center of Disease Control further recommends that visitors to healthcare facilities should be limited in the context of the COVID-19 pandemic, regardless of known community transmission. As a result, hospital intensive care units (ICUs) that provide care to infants and young children have adopted policies that restricted access to visitors and further separated infants from their family [3].

Restrictions on family goes against psychological and neuroscientific evidence in support of unrestricted parental presence for hospitalized infants $[4,5]$. The basic tenet that children in healthcare settings should not be separated from their families regardless of their age, has been endorsed by internationally recognized professional associations [6].

Parents are stable, predictable caregivers who provide unique co-regulation to their infant and should be involved in all aspects of infant care [7-12]. Parent active participation in reciprocal care based on the infant's behavioral patterns and developmental needs within a sensitive period of development in early infancy, is considered imperative 
for infant optimal neurodevelopment [13-16]. Individualized developmental care for hospitalized newborns in ICUs, such as those that have implemented the Newborn Individualized Developmental Care and Assessment Program (NIDCAP), improves neurodevelopment and psychological outcomes for medically fragile infants and their families, and is widely agreed to be the gold standard practice for vulnerable high-risk infants [7, 17-19]. ICUs that provide individualized, developmentally supportive family-centered care, include a soothing environment that encourages sleep and healing and supports attachment and bonding between infants and their families, encourages active parent participation and engagement, while providing continual adjustment of caregiving support to the infant's well-being, strengths and competencies [5, 20-22].

Non-separation of parents and newborns throughout the infant's hospitalization is associated with better medical and developmental outcomes [23]. Parental presence has been linked to reduced prevalence of retinopathy of prematurity, reduced risk of moderate-to-severe bronchopulmonary dysplasia, reduced length of hospitalization, higher breastfeeding rates, reduced parental stress, increased parental competence, and improved neurodevelopmental outcomes [24-29]. In addition, families experience significant mental health concerns when their infants need an intensive care environment, which are significantly ameliorated by frequent contact between family and child, unrestricted access to the infant, family participation in care, and educational and psychosocial support for the family [13].

The purpose of this survey is to explore developmental and family-centered care practices for hospitalized infants and their families during the COVID-19 pandemic, focusing on the implementation of restrictions and the use of supportive strategies to engage parents in the care of their infant. We hypothesized that units with low COVID-19 transmission rate, small units, units with facilities that enable relative isolation (e.g., availability of single-family rooms) and units with healthcare providers trained in developmental care, would adhere to their practices before the pandemic, implement less generalized restrictions and include more individualized support measures for families.

\section{Methods}

\section{Design and sample}

This exploratory descriptive study used an online survey format (google forms) distributed electronically to health care professionals (HCPs) in ICUs working with infants and young children. HCPs affiliated with the NIDCAP Federation International, (NFI), distributed the survey in their respective professional networks using email Listserve communication and social media posts. The study was approved by the Institutional Review Board at Meir Medical Center, Kfar Saba, Israel, and was determined to be exempt prior to survey dissemination and data collection.

\section{Instrument}

The survey was based off a previously published work by Lopez-Maestro et al., and modified items to include language pertinent to infant care before and during COVID-19 [30]. Content validity was obtained via review of current literature and review by newborn and infant cardiac HCPs that were part of the NFI Science Committee, to assure language was appropriate and understandable. The survey included 28 items that explored practices related to family presence and active participation in infant care, skin-to-skin holding, breastfeeding, and psychological support. Ten open-ended questions were included to provide data on current practices and to explore initiatives participants had used to support infants and families during the COVID-19 pandemic. Eleven additional items provided information on demographic characteristics of the hospital units. The COVID-19 infection risk (high, medium, low) in the unit's geographical area was categorized by the respondents according to their own national and/or local definitions. The survey was distributed from mid-May through the beginning of July 2020. Responses were confidential and anonymous with no identifying information collected. Consent was addressed in an introductory letter and inferred given voluntary participation.

\section{Data analysis}

Statistical analysis was performed using SPSS-25 software package. Categorical variables were described with absolute and relative frequencies. Chi-Square Test was used to assess the association between practices and units' characteristics. For variables with more than two possibilities, Bonferroni Correction was used. A $p$ value of $<0.05$ was considered statistically significant.

Template analysis was performed on open-ended items with free-text survey responses [31]. A coding template of distinctive themes was developed based on the textual data, following a stepwise qualitative analysis process [32]. Individual responses were coded according to this template and aggregated to reflect the emergent themes.

\section{Results}

The sample consisted of 96 participants representing 96 different units from 22 countries (Europe, Asia, New Zealand, and North America). Participants worked in the 
Table 1 Characteristics of respondent units.

\begin{tabular}{ll}
\hline Unit characteristics & $n(\%)$ \\
\hline Unit type & \\
Newborn & $75(78.1)$ \\
Cardiac & $16(16.7)$ \\
Pediatric & $5(5.2)$ \\
Unit setting & \\
Intensive care & $91(95.8)$ \\
Step-down & $24(25.3)$ \\
Unit size & \\
$<20$ beds & $20(22.5)$ \\
$20-40$ beds & $41(46.1)$ \\
$>40$ beds & $28(31.4)$ \\
Unit design & \\
Single-family rooms & $25(26.0)$ \\
Multiple-bed rooms & $52(54.2)$ \\
Mixture & $19(19.8)$ \\
Developmental care training & \\
NIDCAP & $38(39.6)$ \\
Other & $46(47.9)$ \\
None & $12(12.5)$ \\
COVID-19 infection rate & \\
Low & $28(30.1)$ \\
Medium & $26(28.0)$ \\
High & $41(44.7)$ \\
\hline &
\end{tabular}

hospital setting and most were from intensive care settings, specifically Newborn ICUs, with a smaller representation of Cardiac and Pediatric units. About half of the units were medium sized (20-40 beds) with almost half utilizing either solely single-family rooms or a mixture of single and multiple-bed rooms. Table 1 describes specific demographic characteristics of the sample.

Prior to the outbreak of the COVID-19 pandemic, practices to promote family presence and participation in care were widely implemented in the respondent units as outlined in Table 2. These included unrestricted access to unit for parent/primary caregiver $(86.5 \%)$, parent/primary caregiver presence in medical rounds $(77.7 \%)$, skin-to-skin holding (92.7\%), and breastfeeding (93.7\%). Psychological support to parents/primary caregivers was available in most of the respondent units $(77.9 \%)$.

Following the outbreak of the COVID-19 pandemic, more than $83 \%$ of the units applied restrictions to parent/ primary caregiver presence, as described in Table 3 . The most common restriction was the allowance for only one family member to be with the infant, practiced in $64 \%$ of the units. Moreover, $10 \%$ of the units restricted access to any family member except the mother, $7 \%$ restricted parent/ primary caregiver presence to specifically determined circumstances (e.g., infant's surgery, end of life, feeding,
Table 2 Care practices before COVID-19 pandemic.

\begin{tabular}{|c|c|c|}
\hline & $N$ & $n(\%)$ \\
\hline \multicolumn{3}{|l|}{ Parents/primary caregivers } \\
\hline Presence welcomed 24/7 & 96 & $83(86.5)$ \\
\hline Presence in medical rounds & 94 & $73(77.7)$ \\
\hline Overnight presence & 96 & $72(75.0)$ \\
\hline Welcomed in medical procedures & 92 & \\
\hline Blood sampling & & $70(76.1)$ \\
\hline Line insertion & & $58(63.0)$ \\
\hline Endotracheal suctioning & & $63(68.5)$ \\
\hline Endotracheal intubation & & $24(26.1)$ \\
\hline Ultrasound examination & & $71(77.2)$ \\
\hline Retinopathy screening & & $54(58.7)$ \\
\hline Encouragement of skin-to-skin care & 96 & $89(92.7)$ \\
\hline Promotion of breastfeeding & 95 & $89(93.7)$ \\
\hline Use of mother's expressed milk & 95 & $90(94.7)$ \\
\hline Grandparents/family caregivers & 96 & \\
\hline Presence welcomed & & $28(29.1)$ \\
\hline Presence restricted & & $41(42.7)$ \\
\hline Presence not allowed & & $27(28.1)$ \\
\hline Siblings & 79 & \\
\hline Presence welcomed & & $20(25.3)$ \\
\hline Presence restricted & & $33(41.8)$ \\
\hline Presence not allowed & & $26(32.9)$ \\
\hline \multicolumn{3}{|l|}{ Psychological support } \\
\hline To parents/primary caregivers & 95 & $74(77.9)$ \\
\hline To health care team & 83 & $30(36.1)$ \\
\hline Online to parents/primary caregivers & 79 & $22(27.8)$ \\
\hline Online to health care team & 80 & $12(15.0)$ \\
\hline
\end{tabular}

discharge teaching), and $7 \%$ limited their presence to allotted times of day. However, parent/primary caregiver participation in care, skin-to-skin holding, breastfeeding, and use of expressed milk were restricted to a lesser extent. The presence of grandparents, siblings, and caregivers other than parents was restricted or not permitted during the pandemic in $87 \%$ of the units. In addition, during the pandemic, psychological support for parents/primary caregivers and HCPs was either not provided or became less available than prior to the outbreak of the pandemic in approximately one-third of the units. Only $16 \%$ of the units increased the psychological support offered to parents/primary caregivers, whereas $31 \%$ increased online psychological support using telehealth approaches.

The association between practices and units' characteristics are shown in Table 4. Restrictions applied to families were not associated to COVID-19 infection risk in the unit's geographical area, to developmental care training of the HCPs and to unit design. Medium-sized (20-40 beds) units applied significantly less restriction than small ( $<20$ beds) units $(p=0.03)$. Even though units with single-family 
Table 3 Changes in care practices during COVID-19 pandemic.

\begin{tabular}{|c|c|c|}
\hline & $N$ & $n(\%)$ \\
\hline Parents/primary caregivers' presence & 96 & \\
\hline Same as before & & $16(16.7)$ \\
\hline Restricted & & $80(83.3)$ \\
\hline Parents/primary caregivers' participation in care & 81 & \\
\hline Same as before & & $56(69.1)$ \\
\hline Restricted & & $26(32.1)$ \\
\hline \multicolumn{3}{|l|}{ Encouragement of skin-to-skin care } \\
\hline Same as before & 96 & $75(78.1)$ \\
\hline Restricted & & $21(21.9)$ \\
\hline \multicolumn{3}{|l|}{ Promotion of breastfeeding } \\
\hline Same as before & 96 & $84(87.5)$ \\
\hline Restricted & & $12(12.5)$ \\
\hline Use of mother's own expressed milk & 94 & \\
\hline Same as before & & $82(87.3)$ \\
\hline Restricted & & $12(12.7)$ \\
\hline Grandparents/Sibling's presence & 95 & \\
\hline Same as before & & $12(12.6)$ \\
\hline Restricted & & $83(87.4)$ \\
\hline \multicolumn{3}{|l|}{$\begin{array}{l}\text { Psychological support for parents/primary } \\
\text { caregivers }\end{array}$} \\
\hline Same as before & 96 & \\
\hline More & & $50(52.1)$ \\
\hline Restricted & & $15(15.6)$ \\
\hline for health care team & & $32(33.3)$ \\
\hline Same as before & 95 & \\
\hline More & & $38(40.0)$ \\
\hline \multirow[t]{2}{*}{ Restricted } & & $17(17.9)$ \\
\hline & & $40(42.1)$ \\
\hline
\end{tabular}

rooms design implemented comparable restrictions to parental presence as units with multiple-bed rooms, units with single-family rooms had significant less restrictions to parents' active participation in care (Table 4, $p=0.03$ ).

The policies implemented during the COVID-19 pandemic were mostly based on national regulations and hospital infection control guidelines $(73 \%$ and $74 \%$ respectively). Approximately one half of the units (52\%) involved their own leadership in policy elaboration, while only $6 \%$ of respondents indicated that either families or national/international parent organizations were included in creating recommendations for parental presence with hospitalized infants. Neither of these factors affected the extent of the restrictions implemented.

Additional initiatives put in place by HCPs to support families during the COVID-19 pandemic were reported in free-text responses by $36 \%$ of the units (Table 5). Respondents described interventions to foster family-infant connectedness (e.g., sharing photos and videos of the infant with the family), to enhance family-staff communication (e.g.,
Table 4 Association between unit characteristics and restrictions applied during the COVID-19 pandemic.

\begin{tabular}{|c|c|c|c|c|c|}
\hline \multicolumn{6}{|c|}{ Parents/primary caregivers' } \\
\hline & $N$ & $\begin{array}{l}\text { Restrictions in } \\
\text { presence } n(\%)\end{array}$ & $p$ & $\begin{array}{l}\text { Restrictions in } \\
\text { care participation } \\
n(\%)\end{array}$ & $p$ \\
\hline \multicolumn{6}{|c|}{ COVID-19 infection rate in geographical area } \\
\hline High & 41 & $32(78)$ & 0.30 & $30(75.0)$ & 0.26 \\
\hline Medium & 25 & $21(84)$ & & $22(88.0)$ & \\
\hline Low & 26 & $24(92)$ & & $18(69.2)$ & \\
\hline \multicolumn{6}{|l|}{ Unit design } \\
\hline $\begin{array}{l}\text { Single- } \\
\text { rooms }\end{array}$ & 25 & $20(80.0)$ & 0.32 & $8(32.0)$ & 0.04 \\
\hline $\begin{array}{l}\text { Multiple- } \\
\text { bed rooms }\end{array}$ & 52 & $42(80.7)$ & & $24(47.1)$ & \\
\hline Mixed & 19 & $18(94.7)$ & & $10(52.6)$ & \\
\hline \multicolumn{6}{|l|}{ Unit size } \\
\hline Small & 20 & $19(95.0)$ & 0.03 & $9(45.0)$ & 0.07 \\
\hline Medium & 41 & $29(70.7)$ & & $5(12.2)$ & \\
\hline Large & 28 & $25(89.3)$ & & $8(28.6)$ & \\
\hline \multicolumn{6}{|c|}{ Developmental care training } \\
\hline NIDCAP & 38 & $29(76.3)$ & 0.29 & $27(71.0)$ & 0.37 \\
\hline Other & 46 & $41(89.1)$ & & $36(78.2)$ & \\
\hline None & 12 & $10(83.3)$ & & $10(83.3)$ & \\
\hline \multicolumn{6}{|c|}{ Involvement of unit leadership in COVID-19 policies } \\
\hline Yes & 49 & $40(81.6)$ & 0.65 & $41(83.6)$ & 0.10 \\
\hline No & 47 & $40(85.1)$ & & $32(68.0)$ & \\
\hline
\end{tabular}

increased briefings with parents), and to create additional resources for families in the unit (e.g., increased support from social work, additional nursing staff). Table 5 shows the complete outline of themes and interventions implemented.

\section{Discussion}

Results from this international survey showcase the wide implementation of developmental care and family-centered care practices before the outbreak of COVID-19 in the respondent units. Prior to the pandemic, most units encouraged skin-to-skin holding, promoted breastfeeding, parental presence, and active participation in infants care, welcomed parents and caregivers to stay overnight and during medical rounds, and offered psychological support to families. However, restrictions to these practices were prevalent following the outbreak of the pandemic, regardless of the unit's previous prevailing practices, the availability of single-family rooms, level of developmental care training for HCPs, or the virus infection rate in the unit's geographical area. Of note, this is different than hypothesized, as we initially considered unit size (i.e., smaller units), 
Table 5 Additional HCPs' and hospital initiatives to support infants and families during COVID-19.

\begin{tabular}{ll}
\hline Theme & Intervention \\
\hline Foster family- infant & Use of digital technology \\
connectedness & Allowance of mobile phone use in the unit \\
& Creation of infant photos/videos \\
& Send photos/videos to families \\
& Encouragement of use of diary \\
& Online visiting \\
& Online medical rounds \\
& Online multidisciplinary rounds \\
Enhance family-staff & Briefings with parents outside unit \\
communication & Telephone calls \\
& Updates about infant situation and changes \\
& Weekly letter, Newsletters \\
& Written information and education \\
& Meals for primary caregiver \\
Create additional & Financial charity support \\
resources & Check-ins from social worker, chaplain, \\
& child life specialist \\
& Proactive outreach to parents by staff \\
& Increased offer of psychological support \\
& Increase in nursing staff \\
& Telehealth for parents' education \\
& Education on COVID-19 prevention \\
& Early discharge and phone follow up \\
Signage in hospital
\end{tabular}

layout (i.e., availability of single rooms), and developmental care training would provide a protection from family restriction measures in the units even during a pandemic.

The current survey focused on the first months of the COVID-19 pandemic outbreak. Limited knowledge on appropriate ways to manage the pandemic prevailed at those initial phases, leading to urgent and generalized measures that involved restrictions for some families of hospitalized infants, regardless of their own COVID-19 infection status [33]. These rapidly adopted restrictions were implemented by HCPs in an effort to minimize the spread of coronavirus. As a deeper understanding of the medical and emotional aspects of the pandemic was gradually gained, concerns about the deleterious effects of parent-infant separation were emphatically raised both by families of hospitalized infants and HCPs [34-36].

Previous research on infant attachment and long-term outcomes of separation indicates that generalized, allencompassing separation policies as those applied during the pandemic in many hospitalization settings, might exert a negative impact on the emergent parent-infant relationship, and consequently on infant development [37-40]. While preserving the concept first do no harm was imperative to individual HCPs [41], adequate safety and protection for infants, families and HCPs from an organizational perspective should be made without jeopardizing basic principles of humane and individualized developmentally supportive care. If given adequate guidance on infection control precautions within the hospitalization units, parents/ primary caregivers who are not suspected of COVID-19 infection, should spend unrestricted time with their infant and remain involved in infant care. Even during the pandemic and in spite of the need for stricter infection precautions, parents and family remain an essential and irreplaceable component in the care and healing process of their hospitalized infant [42]. For many, the substantial benefits of parental participation in the care of their hospitalized infants are considered to outweigh the potential risks of the transmission of COVID-19 [43-45]. Many professional organizations such as the NFI, have posted statements advocating for non-separation for infants and their families during the pandemic.

Recent research highlights the emotional burden experienced by families and health care providers during the COVID-19 pandemic [34, 46]. Data suggest that mothers are at increased risk for depression, anxiety, and posttraumatic stress disorder given the new stressors experienced during the pandemic [47]. Even with this greater need, data from our survey suggest that psychological support offered to families and staff was limited. Less than one-third of the units enhanced the psychological support offered to families and only about one-fifth of the units increased the psychological support provided to staff.

Strategies to ameliorate the consequences of limited visitation have been summarized in a recent publication [48]. Our survey further depicts a variety of novel interventions to support families which were put in place in several hospital units, despite the urgency and apprehension that characterized the first weeks of the pandemic. While some of the interventions to ameliorate the side effects of separation seemingly capitalized on and potentiated practices customary in the units (e.g., the increased use of available virtual technology to keep families connected to their infant), other interventions showcase novel approaches that might not have been used prior to the pandemic (e.g., the incremented use of briefings and weekly letters to parents; additional nursing staff; participation in online rounds). The variety of interventions reported in this survey, used during the acute phases of the COVID-19 health crisis, might provide a useful starting point to elaborate necessary future strategies to enhance and protect individualized, family-centered, developmental care practices not only during pandemic outbreaks, but after its conclusion.

\section{Limitations}

Although the survey was previously published with sound parametric qualities, items were adapted to inquire about experiences pertaining to COVID-19. While the new questions went through content validity testing, they were not pilot tested for reliability prior to the administration of 
the survey. In addition, the survey was conducted during the peak of COVID-19 and it is unclear if policies have changed so far, with added knowledge regarding the virus. Moreover, the target population of HCPs was approached through professional organizations and social media, making the response rate unclear. The study contains a relatively small sample size and there may have been self-report bias as participants' responses were anonymous and confidential to minimize this risk. These limitations generate caution in generalizing the findings.

\section{Conclusion}

The current study provides evidence to examine the care for infants and their families during the COVID-19 pandemic. Data from participants from 22 countries suggest, that many units placed restrictions to family and parent presence in hospitals and increased the separation between parent and child. Placement of restrictions were not related to unit characteristics such as availability of single-rooms, level of education on developmental care, or prevailing infection rates. Hospital systems should use innovative approaches to actively engage parents in the care of their infant while maintaining the safety and security. An important next step is to integrate parents into the decision-making process to assure that national and/or international parent organizations play an important role in developing and implementing standards of care for hospitalized infants during a pandemic.

Acknowledgements The authors would like to thank all the participants that completed the survey. We are deeply appreciative of the healthcare professionals around the world who put their lives in danger every day to care for infants and families especially during this pandemic.

Author contributions All authors designed the survey and submitted the survey via social media. IL and DS wrote the initial draft of the manuscript and provided initial data analyses. SB and DV provided clinical expertise for the interpretation of the study findings, provided edits to the manuscript, and finalized the manuscript.

\section{Compliance with ethical standards}

Conflict of interest The authors declare no competing interests.

Publisher's note Springer Nature remains neutral with regard to jurisdictional claims in published maps and institutional affiliations.

\section{References}

1. Centers for Disease Control and Prevention. COVID-19 Dashboard by the Center for Systems Science and Engineering (CSSE). John Hopkins University; 2020. https://www.cdc.gov/corona virus/2019-ncov/about/index.html
2. World Health Organization. COVID-19: Resources for Pregnancy, Childbirth, and Postnatal Care. 2020. https://www.who.int/ maternal_child_adolescent/links/covid-19-mncah-resources-forpregnancy-childbirth-postnatalcare/en.

3. Cavicchiolo ME, Lolli E, Trevisanuto D, Baraldi E. Managing a tertiary-level NICU in the time of COVID-19: Lessons learned from a high-risk zone. Pediatr Pulm. 2020;55:1308.

4. Moen A. If parents were a drug? Acta Paediatr. If parents were a drug? Acta Paediatr. 2020;109:1709-10.

5. Roué J-M, Kuhn P, Maestro ML, Maastrup RA, Mitanchez D, Westrup B, et al. Eight principles for patient-centred and familycentred care for newborns in the neonatal intensive care unit. Arch Dis Child Fetal Neonatal Ed. 2017;102:F364-F8.

6. European Association for Children in Hospital (EACH). Convention on the Rights of the Child. 2020. http://www.each-forsick-children.org.

7. Als H, Duffy F, McAnulty GB, Rivkin MJ, Vajapeyam S, Mulkern RV, et al. Early experience alters brain function and structure. Pediatrics. 2004;113:846-57.

8. Als H, Lawhon G, Brown E, Gibes R, Duffy FH, McAnulty GB, et al. Individualized behavioral and environmental care for the very low birth weight preterm infant at high risk for bronchopulmonary dysplasia: Neonatal Intensive Care Unit and developmental outcome. Pediatrics. 1986;78:1123-32.

9. Winnicott DW. Babies and their mothers. Beverly, Massachussetts: Da Capo Press; 1987.

10. Fonagy P. Affect regulation, mentalization, and the development of the self. New York: Other Press; 2002.

11. Stern DN. The interpersonal world of the infant: a view from psychoanalysis and developmental psychology: Routledge; 1985.

12. Yu X, Zhang J. Family-centred care for hospitalized preterm infants: a systematic review and meta-analysis. Int J Nurs Pract. 2019;25:e12705

13. Feldman R. Sensitive periods in human social development: new insights from research on oxytocin, synchrony, and high-risk parenting. Dev Psychopathol. 2015;27:369-95.

14. Vittner D, Butler S, Smith K, Makris N, Brownell E, Samra H, et al. Parent engagement correlates with parent and preterm infant oxytocin release during skin-to-skin contact. Adv Neonatal Care. 2019;19:73-9.

15. Forcada-Guex M, Pierrehumbert B, Borghini A, Moessinger A, Muller-Nix C. Early dyadic patterns of mother-infant interactions and outcomes of prematurity at 18 months. Pediatrics. 2006;118: e107-e14.

16. Mehler K, Wendrich D, Kissgen R, Roth B, Oberthuer A, Pillekamp F, et al. Mothers seeing their VLBW infants within $3 \mathrm{~h}$ after birth are more likely to establish a secure attachment behavior: evidence of a sensitive period with preterm infants? J Perinatol. 2011;31:404-10.

17. Lisanti AJ, Vittner D, Medoff-Cooper B, Fogel J, Wernovsky G, Butler S. Individualized family-centered developmental care: an essential model to address the unique needs of infants with congenital heart disease. J Cardiovasc Nurs. 2019;34:85-93.

18. Warren I, Westrup B, Kuhn P. European standards of care for newborn health: education and training for infant- and familycentered developmental care (IFCDC). Munich: Germany; 2018. https://newborn-health-standards.org/education-training-ifcdc.

19. Westrup B. Newborn individualized developmental care and assessment program (nidcap): family-centered developmentally supportive care. NeoReviews. 2005;6:e115-e22.

20. Als H, Butler S, Kosta S, McAnulty G. The assessment of preterm infants' behavior (APIB): Furthering the understanding and measurement of neurodevelopmental competence in preterm and fullterm infants. Ment Retard Dev Disab Res Rev. 2005;11:94-102. 
21. Als H. Caring for the preterm infant: earliest brain development and experience. In: Ramenghi LA, Évrard P, Mercuri E, editors. Perinatal brain damage: from pathogenesis to neuroprotection: John Libbey Eurotext; 2008. p. 233-40.

22. Kleberg A, Hellström-Westas L, Widström A-M. Mothers' perception of Newborn Individualized Developmental Care and Assessment Program (NIDCAP) as compared to conventional care. Early Hum Devel. 2007;83:403-11.

23. Lv B, Gao X-R, Sun J, Li T-T, Liu Z-Y, Zhu L-H, et al. Familycentered care improves clinical outcomes of very-low-birth-weight infants: a quasi-experimental study. Front Pediatr. 2019;7:138.

24. McAnulty G, Duffy FH, Kosta S, Weisenfeld NI, Warfield SK, Butler SC, et al. School-age effects of the newborn individualized developmental care and assessment program for preterm infants with intrauterine growth restriction: preliminary findings. BMC Pediatr. 2013;13:25.

25. O'Brien K, Bracht M, Macdonell K, McBride T, Robson K, O'Leary L, et al. A pilot cohort analytic study of Family Integrated Care in a Canadian neonatal intensive care unit. BMC Pregnancy Childbirth. 2013;13:S12.

26. Lyngstad LT, Steinnes S. Smerte prosjektet COMFORTneo. Sykepleien. 2017;105:62277.

27. Örtenstrand A, Westrup B, Broström EB, Sarman I, Åkerström S, Brune T, et al. The Stockholm Neonatal Family Centered Care Study: effects on length of stay and infant morbidity. Pediatrics. 2010;125:e278-85.

28. Pineda R, Bender J, Hall B, Shabosky L, Annecca A, Smith J. Parent participation in the neonatal intensive care unit: predictors and relationships to neurobehavior and developmental outcomes. Early Hum Devel. 2018;117:32-8.

29. Reynolds LC, Duncan MM, Smith GC, Mathur A, Neil J, Inder T, et al. Parental presence and holding in the neonatal intensive care unit and associations with early neurobehavior. J Perinatol. 2013;33:636-41.

30. Lopez-Maestro M, De la Cruz J, Perapoch-Lopez J, GimenoNavarro A, Vazquez-Roman S, Alonso-Diaz C, et al. Eight principles for newborn care in neonatal units: Findings from a national survey. Acta Paediatr. 2020;109:1361-8.

31. Brooks J, McCluskey S, Turley E, King N. The utility of template analysis in qualitative psychology research. Qual Res Psychol. 2015;12:202-22

32. King N. Doing Template Analysis. In: Symon G, Casell C, editors. Qualitative organizational research. London: Sage; 2012. p. 426-50.

33. Duran P, Berman S, Niermeyer S, Jaenisch T, Forster T, Gomez Ponce de Leon R, et al. COVID-19 and newborn health: systematic review. Rev Pan Salud Pública. 2020;44:e54.
34. Erdei $\mathrm{C}$, Liu CH. The downstream effects of COVID-19: a call for supporting family wellbeing in the NICU. $J$ Perinatol. 2020;40:1283-5.

35. Liu CH, Doan SN. Psychosocial stress contagion in children and families during the COVID-19 pandemic. Cin. Pediatrics. 2020;59:853-5.

36. Irish Neonatal Health Aliances https://www.inha.ie.

37. Bowlby J. Attachment and Loss. New York: Basic Books; 1969.

38. Conde-Agudelo A, Díaz-Rossello JL. Kangaroo mother care to reduce morbidity and mortality in low birthweight infants. Cochrane Database Syst Rev. 2016(8):CD002771.

39. Hofer MA. Hidden regulators: Implications for a new understanding of attachment, separation, and loss. In: Goldberg S, Muir R, Kerr J, editors. Attachment theory: Social, developmental, and clinical perspectives. Analytic Press, Inc.; 1995 p. 203-30.

40. Weiss SJ, Wilson P, Seed MSJ, Paul SM. Early tactile experience of low birth weight children: Links to later mental health and social adaptation. Infant Child Dev. 2001;10:93-115.

41. Stuebe A. Should infants be separated from mothers with COVID19? First, do no harm. Breastfeed Med. 2020;15:351-2.

42. Als H, Butler S. Newborn Individualized Developmental Care and Assessment Program (NIDCAP): Changing the Future for Infants and Families in Intensive and Special Care Nurseries. Early Child Serv. 2008;2:1-19.

43. Davanzo R, Merewood A, Manzoni P. Skin-to-Skin Contact at Birth in the COVID-19 Era: In Need of Help! Am J Perinatol. 2020;37:S1-S4.

44. Lackey KA, Pace RM, Williams JE, Bode L, Donovan SM, Järvinen $\mathrm{KM}$, et al. SARS-CoV-2 and human milk: What is the evidence? Matern Child Nutr. 2020;16:e13032.

45. Renfrew MJ, Cheyne H, Dykes F, Entwistle F, McGuire W, Shenker $\mathrm{N}$, et al. Optimising mother-baby contact and infant feeding in a pandemic. Royal College of Midwives. 2020. https://www.rcm.org.uk/media/4142/optimising-mother-ba by-contact-and-infant-feeding-in-a-pandemic-version-2-final24th-june-2020.pdf. Accessed July 10, 2020.

46. Wang J, Qi H, Bao L, Li F, Shi Y. A contingency plan for the management of the 2019 novel coronavirus outbreak in neonatal intensive care units. Lancet Child Adolesc Health. 2020;4:258-9.

47. Thapa SB, Mainali A, Schwank SE, Acharya G. Maternal mental health in the time of the COVID-19 pandemic. Acta Obstet Gynecol Scand. 2020;99:817-18.

48. Murray PD, Swanson JR. Visitation restrictions: is it right and how do we support families in the NICU during COVID-19? J Perinatol. 2020;40:1576-81. 